\title{
Perkembangan Folikel dan Munculnya Estrus setelah Penyuntikan GnRH pada Sapi Bali yang Mengalami Anestrus Postpartum dengan Body Condition Score Berbeda
}

\author{
(FOLLICULAR DEVELOPMENT AND THE ONSET OF ESTRUS DUE TO INDUCTION \\ OF GNRH IN BALI CATTLE ANESTRUS POSTPARTUM WITH DIFFERENT BODY \\ CONDITION SCORE)
}

\section{Nyoman Oka Widiarta ${ }^{1 *}$, Tjok Gde Oka Pemayun², I Gusti Ngurah Bagus Trilaksana²}

1Puskeswan Sobangan Dinas Pertanian dan Pangan Kabupaten Badung, Bali. 'Laboratorium Reproduksi Veteriner Fakultas Kedokteran Hewan Universitas Udayana, Jl. PB. Sudirman, Denpasar, Bali.*Email: oka.widi015@gmail.com

\begin{abstract}
ABSTRAK
Penelitian ini bertujuan untuk mengetahui perkembangan folikel dan munculnya estrus setelah penyuntikan GnRH pada sapi bali yang mengalami anestrus postpartum lebih dari tiga bulan dengan body condition score (BCS) berbeda di Kabupaten Badung, Bali. Rancangan yang digunakan pada penelitian ini adalah rancangan acak lengkap (RAL) yang terdiri dari tiga kelompok perlakuan yaitu kelompok I : sapi bali yang mengalami anestrus postpartum dengan BCS 2, kelompok II : sapi bali yang mengalami anestrus postpartum dengan BCS 3 , kelompok III : sapi bali yang mengalami anestrus postpartum dengan BCS 4 dan masing-masing kelompok terdiri dari 9 ulangan . Ketiga kelompok sapi ini disuntik GnRH (Fertagyl,Intervet Inc) dengan dosis $500 \mu \mathrm{g} / \mathrm{im} / \mathrm{ekor}$. Hasil penelitian menunjukkan rataan ukuran folikel sebelum penyuntikan $\mathrm{GnRH}$ adalah $4.03 \pm 0.21 \mathrm{~mm}, 4.60 \pm 0.18 \mathrm{~mm}, 4.56 \pm 0.22$ mm masing-masing untuk BCS 2, BCS 3 dan BCS 4 dan rataan ukuran folikel setelah penyuntikan GnRH adalah $7.08 \pm 0.42 \mathrm{~mm}, 11.06 \pm 0.40 \mathrm{~mm}$ dan $11.99 \pm 0.33$ masing-masing untuk BCS 2 , BCS 3 dan BCS 4 dan secara statistik menunjukkan perbedaan yang nyata $(\mathrm{P}<0,05)$. Waktu munculnya estrus pada ketiga kelompok perlakuan adalah $7.75 \pm 0.89$ hari, $4.63 \pm 0.52$ hari dan $3.63 \pm 0.52$ hari, masingmasing untuk BCS 2, BCS 3 dan BCS 4 dan secara statistik menunjukkan perbedaan yang nyata $(\mathrm{P}<0,05)$. Ukuran diameter folikel terbesar diperoleh pada sapi bali yang mempunyai BCS 4 yaitu sebesar 11,99 $\pm 0,33 \mathrm{~mm}$ dengan waktu munculnya estrus $3.63 \pm 0.52$ hari. Hasil penelitian dapat disimpulkan bahwa penyuntikan GnRH 500 $\mathrm{g}$, mampu meningkatkan perkembangan folikel dan menginduksi munculnya estrus pada sapi bali yang mengalami anestrus postpartum.
\end{abstract}

Kata kunci: Folikel ovarium; estrus; GnRH, sapi bali; BCS

\begin{abstract}
This study aim to determine the development of follicles and onset of estrus due to GnRH induction in bali cattle which has anestrus postpartum more than three month with differnt body condition score in the Badung regency of Bali.The designd used in this study was a complete random design were divided into three treatment groups, namely Group 1 : cattle with BCS 2, Group 2 : cattle with BCS 3, Group 3 : cattle with BCS 4, each group consisted of 9 replication. All of group of bali cattle are induced by GnRH (Fertagyl, Intervet,Inc) at a dose of 500 $\mu \mathrm{g} / \mathrm{IM} / \mathrm{cattle}$. The result of this study indicate the development of follicles averages before induction of GnRH is $4.03 \pm 0.21 \mathrm{~mm}, 4.60 \pm 0.18 \mathrm{~mm}$, $4.56 \pm 0.22 \mathrm{~mm}$, each for BCS2, BCS 3 and BCS 4 and development of follicles averages after induction of GnRH is $7.08 \pm 0.42 \mathrm{~mm}, 11.06 \pm 0.40 \mathrm{~mm}$ and $11.99 \pm 0.33$ each for BCS 2 , BCS 3 and BCS 4 and statistically shows that there are significant differences $(\mathrm{P}<0,05)$. The averages onset of estrus in the three treatment group is $7.75 \pm 0.89$ day, $4.63 \pm 0.52$ day dan $3.63 \pm 0.52$ day, each for BCS 2 , BCS 3 and BCS 4 and statistically shows that there are significant differences $(\mathrm{P}<0,05)$. The largest follicular diameter in BCS 4 is $11,99 \pm 0,33 \mathrm{~mm}$ with the time of onset of estrus 3,63 $\pm 0,52$ day. The result can be concluded that the induction of GnRH 500ug in bali cattle can increase follicular development and accelerate the oset of estrous.
\end{abstract}

Keywords: Development of follicles ovary; estrus; GnRH; bali cattle; BCS. 


\section{PENDAHULUAN}

Masalah yang banyak dihadapi oleh peternak di Bali adalah panjangnya calving interval akibat tidak munculnya estrus lebih dari tiga bulan setelah melahirkan, tingginya kasus anestrus postpartum mengakibatkan lambatnya laju populasi (Laksmi et al., 2019). Nitis dan Pemayun (2000) melaporkan kasus anestrus postpartum pada sapi bali yaitu rata-rata 4,11 bulan dan panjangnya calving interval dengan rata-rata 14,83 bulan.

Kegagalan reproduksi merupakan salah satu faktor utama yang dapat menghambat laju perkembangan populasi ternak. Untuk dapat melahirkan satu anak dalam setahun setiap induk sapi umumnya calving interval tidak lebih dari 365 hari dan kembali estrus tidak lebih dari tiga bulan setelah melahirkan (Opsomer and de Kruif, 1999). Anestrus postpartum sering merupakan penyebab infertilitas pada sapi. Gangguan reproduksi ini umumnya terjadi pada sapi induk sesudah partus atau inseminasi / perkawinan tanpa terjadi konsepsi. Menurut Kesler and Garverick (1982), anestrus pada sapi disebabkan oleh berbagai faktor diantaranya gangguan hormonal, perubahan lingkungan, manajemen pakan yang kurang baik dan penyakit.

Nutrisi merupakan faktor penyebab terjadinya gangguan reproduksi sapi potong di daerah tropis (Besung et al., 2019). Nutrisi dan cadangan energi tubuh dibutuhkan dalam proses metabolisme, sintesis hormon reproduksi, pertumbuhan, laktasi dan aktivitas reproduksi. Arthur (1982) menyatakan bahwa body condition score yang rendah, kondisi tubuh yang kurang baik dan stress saat laktasi dapat memperpanjang periode anestrus. Hal ini akan mempengaruhi fungsi hipofisa anterior sehingga produksi dan skresi hormon FSH dan LH rendah yang menyebabkan ovarium tidak berkembang atau mengalami hipofungsi (Noakes et al.,
2001). Menurut Hafez (2000) bahwa anestrus akibat hipofungsi ovarium sering berhubungan dengan gagalnya selsel folikel menanggapi rangsangan hormonal, adanya perubahan kuantitas maupun kualitas sekresi hormonal, menurunnya rangsangan yang berhubungan dengan fungsi hipotalamuspituitaria-ovarium yang akan menyebabkan menurunnya sekresi gonadotropin sehingga tidak ada aktivitas ovarium setelah melahirkan. Beberapa peneliti telah melaporkan bahwa untuk merangsang aktivitas ovarium pada kasus anestrus postpartum dengan penyuntikan hormon gonadotropin pada sapi (Hafez, 2000). Penyuntikan GnRH pada sapi potong (Yavas and Walton, 2003) dan penyuntikan GnRH pada sapi perah (Pemayun, 2009) Penelitian ini bertujuan untuk mengetahui perkembangan folikel, dan munculnya estrus setelah penyuntikan GnRH 500 $\mu \mathrm{g}$ pada sapi bali yang mengalami anestrus postpartum dengan body condition score berbeda

\section{METODE PENELITIAN}

Penelitian ini menggunakan 27 ekor sapi bali yang mengalami anestrus postpartum lebih dari tiga bulan dengan body condition score (BCS) yang berbeda di peternakan yang ada di kabupaten Badung. Penentuan anestrus postpartum dilakukan dengan melakukan palpasi rektal pada sapi yang tidak menunjukkan tanda estrus yang ditandai dengan ovarium berukuran normal dengan permukaan yang licin karena tidak ada perkembangan folikel dan corpus luteum. Pakan yang diberikan adalah jerami padi, batang pisang, rumput raja, hijauan dan konsentrat. Sistem pemeliharaan dengan kandang koloni dimana sapi tidak pernah dikelurkan dari kandang dan tanpa diberikan exercise.

Rancangan yang digunakan pada penelitian ini adalah rancangan acak lengkap (RAL) yang terdiri dari tiga kelompok perlakuan yaitu kelompok I: 
sapi bali yang mengalami anestrus postpartum dengan BCS 2, kelompok II: sapi bali yang mengalami anestrus postpartum dengan BCS 3, kelompok III: sapi bali yang mengalami anestrus postpartum dengan BCS 4 dan masingmasing kelompok terdiri dari 9 ulangan. Ketiga kelompok sapi ini disuntik GnRH (Fertagyl,Intervet Inc) dengan dosis $500 \mu \mathrm{g} / \mathrm{im} / \mathrm{ekor}$.

Parameter yang diukur pada penelitian ini adalah perkembangan folikel yang diukur dengan USG (KX 5200, KAIXIN), yaitu sebelum penyuntikan GnRH dan pada saat muncul estrus. Munculnya estrus setelah penyuntikan GnRH yang ditandai dengan keluarnya lendir, perubahan kondisi vulva (merah, bengkak, basah), gelisah dan nafsu makan menurun, menaiki dan diam dinaiki sesamam sapi betina (Hafez, 2000). Pengamatan terhadap munculnya estrus dilakukan dua kali sehari yaitu pagi pukul 06.00-07.00 WITA dan sore hari pukul 17.00-18.00 WITA.

\section{Analisis Statistik}

Data yang diperoleh di tabulasi dan dianalisis statistik dengan program excel 2017 for windows.

\section{HASIL DAN PEMBAHASAN}

Hasil penelitian menunjukkan bahwa rataan ukuran folikel sebelum penyuntikan $\mathrm{GnRH}$ adalah $4.03 \pm 0.21$ $\mathrm{mm}, 4.60 \pm 0.18 \mathrm{~mm}, 4.56 \pm 0.22 \mathrm{~mm}$ masing-masing untuk BCS 2, BCS 3 dan BCS 4 dan rataan ukuran Folikel setelah penyuntikan $\mathrm{GnRH}$ adalah $7.08 \pm$ $0.42 \mathrm{~mm}, 11.06 \pm 0.40 \mathrm{~mm}$ dan $11.99 \pm$ 0.33 masing-masing untuk BCS $2, \mathrm{BCS}$ 3 dan BCS 4 (Tabel 1). Dari hasil paparan diatas secara statistik menunjukkan perbedaan yang nyata $(\mathrm{P}<0,05)$ terhadap diameter folikel sebelum dan sesudah penyuntikan GnRH antara kelompok I,II dan III. Perbedaan diameter folikel ovarium sebelum dan sesudah penyuntikan GnRH lebih jelas dapat dilihat pada gambar 1 .

Tabel 1. Rata-rata ( $\bar{x}+\mathrm{SD})$ Diameter Folikel Ovarium (mm) sebelum dan sesudah pemberian Gn-RH

\begin{tabular}{lll}
\hline \multirow{2}{*}{ Kelompok } & \multicolumn{2}{c}{ Diameter Folikel $(\mathrm{mm})$} \\
\cline { 2 - 3 } & Awal $(\bar{x} \pm$ SD $)$ & Akhir $(\bar{x} \pm$ SD) \\
\hline BCS 2 & $4.03 \pm 0.21^{\mathrm{a}}$ & $7.08 \pm 0.42^{\mathrm{b}}$ \\
BCS 3 & $4.60 \pm 0.18^{\mathrm{a}}$ & $11.06 \pm 0.40^{\mathrm{b}}$ \\
BCS 4 & $4.56 \pm 0.22^{\mathrm{a}}$ & $11.99 \pm 0.33^{\mathrm{b}}$ \\
\hline
\end{tabular}

Ket: Huruf yang berbeda pada baris yang sama adalah perbedaan yang nyata pada tatanan $5 \%(P<0,05)$.
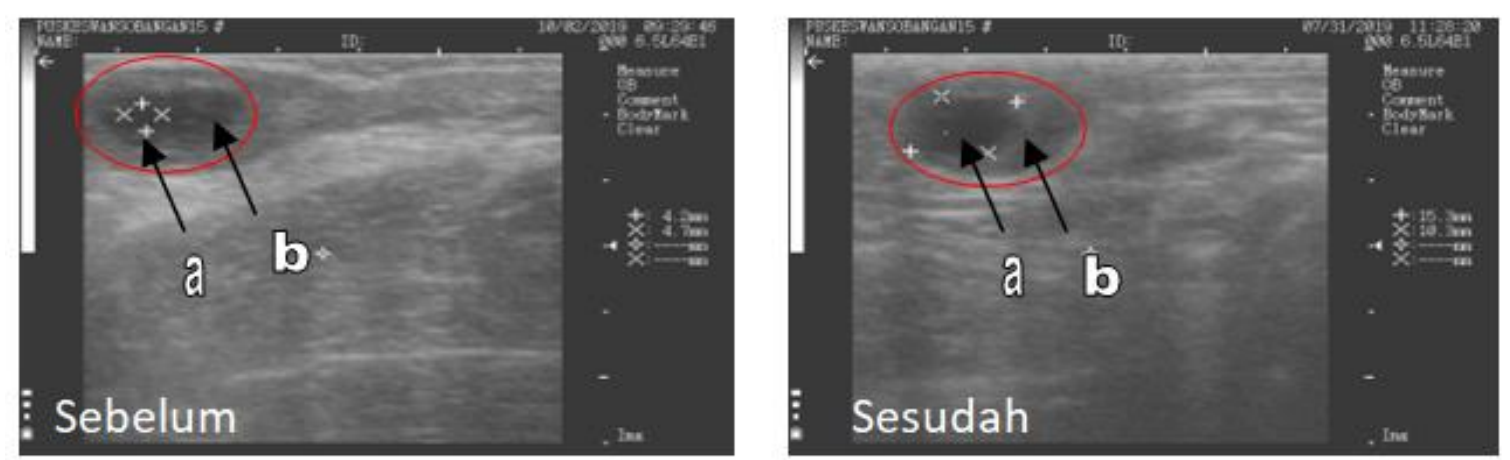

Gambar 1. diameter folikel sebelum dan sesudah diberikan GnRH $500 \mu \mathrm{g}$ (a.folikel ovarium, b. Ovarium) 
Rataan terhadap munculnya estrus pada ketiga kelompok perlakuan setelah penyuntikan $\mathrm{GnRH}$ adalah $7.75 \pm 0.89$ hari, $4.63 \pm 0.52$ hari dan $3.63 \pm 0.52$ hari, masing-masing untuk BCS 2, BCS 3 dan BCS 4.Waktu munculnya estrus secara statistik menunjukkan perbedaan yang nyata $(\mathrm{P}<0,05)$ sesudah penyuntikan GnRH antara Kelompok I, II dan III. Perbedaan waktu munculnya estrus sesudah penyuntikan GnRH antara kelompok I, II dan III lebih jelas dapat dilihat pada diagram 1.

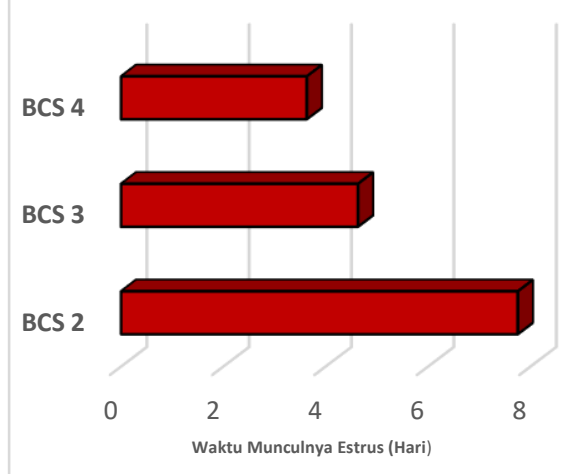

Diagram 1. waktu munculnya estrus sesudah penyuntikan $\mathrm{GnRH}$

Aktivitas ovarium setelah melahirkan merupakan hal yang sangat penting harus diperhatikan untuk bisa meningkatkan perfoman reproduksi. Berkembang dan berfungsinya organ reproduksi setelah melahirkan tergantung dari kadar LH dan FSH dari hipofisa anterior yang dikontrol oleh GnRH yang diskresikan oleh hypothalamus dan selain itu status pakan setelah melahirkan sangat berpengaruh terhadap sekresi hormon gonadotrophin (Miller et al., 1998).

Hasil penelitian ini menunjukkan bahwa terjadi peningkatan perkembangan folikel dan munculnya estrus pada sapi bali yang mengalami anestrus postpartum setelah pemberian GnRH. Hal ini sesuai dengan kerja hormon seperti yang dilaporkan oleh Hafez (2000) bahwa GnRH berfungsi mengiduksi pelepasan FSH dan LH di Hipofisa anterior sehingga dapat menyebabkan folikel dan terjadinya estrus. Sesuai dengan penelitian yang dilakukan oleh Putro (2014 ) menunjukkan bahwa pemberian Gn-RH mampu meningkatkan diameter folikel ovulasi secara nyata dengan diameter folikel $14,40 \mathrm{~mm}$. Adanya perbedaan ukuran diameter folikel dipengaruhi status nutrisi. Status nutrisi dan cadangan energi tubuh dapat dievaluasi secara klinis melalui BCS. Body condition score erat hubungannya dengan cadangan lemak tubuh, dimana diketahui jumlah simpanan lemak tubuh mempengaruhi fertilitas dan proses steroidogenesis. Hal ini mengindikasikan bahwa adanya kaitan erat antara jaringan adiposa dan sistem reproduksi (Leifers,2004). Perbaikan nutrisi yang meliputi kuantitas dan kualitas harus dilakukan pada sapi sapi yang memiliki BCS $<2$ sebelum terapi hormonal akan memberikan hasil yang optimal. Adanya interaksi yang komplek antara antara faktor lingkungan atau manajemen (nutrisi), respon individual dan derajat keparahan akan menimbulkan respon kesembuhan yang berbeda (Budiyanto et al., 2016).

Mihm and Bleach (2003), menyatakan perbedaan gizi dan status reproduksi dapat mempengaruhi pelepasan GnRH dan LH selama periode postpartum pada sapi perah akibat keseimbangan energy negatif. Keseimbangan energi negatif dapat terjadi pada pada sapi perah dengan skor kondisi tubuh yang rendah. Status metabolisme hewan akibat keseimbangan energi negatif akan mempengaruhi sirkulasi berbagai hormon seperti leptin, insulin, GH, IGF-1, kortisol atau tiroksin yang berpengaruh terhadap proliferasi sel-sel folikuler sapi dan steroidogenesis. Hormon metabolik seperti IGF-1 merupakan mediator intake makanan dan / atau keseimbangan energi terhadap fertilitas sapi yang berperan dalam perkembangan folikel (Diskin et al., 2013). Kurangnya asupan nutrisi akan mempengaruhi senyawa metabolisme 
dan hormon seperti insulin dan insulin like growth-I yang mempengaruhi hipothalamus dan hipofisa terhadap respon ovarium dan sensitifitas $\mathrm{GnRH}$ pada hipofisis sehingga energy tubuh akan menekan pelepasan GnRH dan mempengaruhi pulsatile LH yang diperlukan untuk pertumbuhan folikel. (Budiyanto et al., 2016). Ukuran folikel de graff yang berkembang cepat dan mencapai ukuran maksimal akan meningkatkan konsentrasi estrogen dalam cairan folikuli folikel ovarium menjadi optimal sehingga menginisiasi terjadinya estrus dengan tampilan birahi lebih jelas (Budiyanto, 2018)

Timbulnya estrus pada penelitian ini setelah penyuntikan GnRH $500 \mu \mathrm{g}$ tidak jauh berbeda seperti yang dilaporkan sebelumnya munculnya estrus rata-rata 7,17 $\pm 3,24$ hari dengan kisaran hari 5-10 hari (Pemayun, 2009). Panjang pendeknya waktu munculnya estrus sangat dipengaruhi oleh peningkatan perkembangan folikel dimana faktor nutrisi sangat berperan penting dalam metabolisme dan sintesis hormon. Semakin tinggi BCS respon terhadap pemberian hormon semakin bagus, ini berkaitan dengan nutrisi dimana kekurangan pakan dalam kurun waktu yang lama pada sapi akan menyebabkan GnRH tidak di respon secara aktif di hipofisa anterior sehingga terjadi penurunan pertumbuhan folikel dominan secara bertahap sehingga tidak mencapai folikel maksimum (Diskin et al., 2003).

Menurut Bossis et al. (1999) dan Butler (2000), konsumsi energi meningkatkan glukosa darah dan insulin yang dapat meningkatkan getaran sekresi LH dan memperbaiki tanggap ovarium terhadap stimulasi LH, LH diperlukan untuk pertumbuhan folikel. Peningkatan perkembangan folikel ini membawa konsekuensi peningkatan kadar estrogen dalam darah. Estrogen selain menimbulkan estrus pada sapi, juga memacu efek umpan balik positifnya terhadap LH (Hafez,2000). Munculnya estrus yang lebih cepat dipengaruhi karena kadar estrogen lebih tinggi yang disebabkan oleh jumlah folikel yang tumbuh dan berkembang lebih banyak dan lebih cepat (Pemayun,2009).

\section{SIMPULAN}

\section{Simpulan}

Dari hasil penelitian dapat disimpulkan bahwa pemberian GnRH $500 \mu \mathrm{g}$ mampu meningkatkan perkembangan folikel dan menginduksi munculnya estrus pada sapi bali yang mengalami anestrus postpartum, dimana sapi dengan BCS 4 menunjukkan diameter folikel terbesar sebesar $11,99 \pm 0,33 \mathrm{~mm}$ dengan waktu munculnya estrus tercepat yaitu $3,63 \pm$ 0,52 hari.

\section{Saran}

Perlu dilakukan perbaikan nutrisi pada sapi dengan BCS 2 sebelum dilakukan penyuntikan GnRH dan perlu diberikan exercise pada sapi dengan BCS 3 dan BCS 4.

\section{UCAPAN TERIMAKASIH}

Penulis mengucapkan terimakasih kepada Departemen Reproduksi FKH Udayana, dan Dinas Pertanian dan Pangan Kabupaten Badung atas dukungannya dalam memfasilitasi penelitian ini.

\section{DAFTAR PUSTAKA}

Arthur GH. 1982. Veterinary Reproduction and Obstetrics. $5^{\text {th }}$ Ed. Bailleire Tindall, London, UK. Pp. 616.

Besung INK, Watiniasih NL, Mahardika IGNK, Agustina KK, Suwiti NK. 2019. Mineral levels of Bali cattle (Bos javanicus) from different types of land in Bali, Nusa Penida, and Sumbawa Islands (Indonesia). Biodiversitas. 20(10): 2931-2936.

Bossis I, Wettemann RP, Welly SD, Vizcarra JA, Spiceer LJ, Diskin MG. 1999. Nutionally induced anovulation in beef heifers ovarian and endocrine 
function presceeding cessation of ovulation. J. Anim. Sci. 77: 15361546.

Budiyanto A, Thopianong TC, Triguntoro, Dewi HK. 2016. Gangguan reproduksi sapi bali pada pola pemeliharaan semi intensif di daerah sistem integrasi sapi - kelapa sawit. Acta Veterinaria Indonesiana. 4(1): 14-18

Budiyanto A. 2018. Faktor Gangguan Reproduksi Di Indonesia Dalam Manajemen Breeding Sapi Potong. Disampaikan dalam acara refreshing untuk Dosen Pembimbing Lapangan Koassistensi, Departemen Reproduksi FKH UGM, 21 September 2018.

Buttler WR. 2000. Nutritional interaction with reproduktive perfomance in dairy cattle. Anim. Reprod. Sci. 6061: 449-457.

Diskin MG, Mackey DR, Roche JF, Sreenan JM. 2003. Effects of nutrition and metabolic status on circulating hormones and ovarian follicle develpoment cattle. Anim. Reprod. Sci. 78: 345-370.

Hafez ESE. 2000. Reproduction in farm animal. Edition $7^{\text {th }}$ Ed. Lippncott Williams \& Wilkins. Maryland. USA.

Kesler DJ, Garverick HA. 1982. Ovarian cysts in dairy cattle: A review. $J$. Anim. Sci. 55: 1147-1159.

Laksmi DNDI, Trilaksana IGNB, Darmanta RJ, Darwan M, Bebas IW, Agustina KK. 2019. Correlation between body condition score and hormone level of Bali cattle with postpartum anestrus. Indian J. Anim. Res. 53(12): 1599-1603.

Liefers S. 2004. Physiologi and Genetics of Leptin in Periparturient Dairy Cows. (Ph.D. Thesis). Animal Breeding and Genetics, Wageningen
University, Wanginengen and Division of Animal Resources Development, Animal Science Group, Lelystad. ISBN 90-5808-9983.

Mihm M, Bleach ECL. 2003. Endocrine regulation of ovarian antral follicle development in cattle. Anim. Reprod. Sci. 78: 217-237.

Miller DW, Blanche D, Boukhliq R, Curlewis JD, Martin GB. 1998. Central metabolic messenger and the effect of nutrition on gonadotrophin scretion in sheep. J. Reprod. Fertility. 112: 347-356.

Nitis IM, Lana K, Sukanten W, Pemayun TGO, Puger AW. 1994. Growth and Reproductive Performance of Bali Heifer under Three Strata Forage System. Report to FAO. Project No. AGAP-653AN 40/5. Rome.

Noakes DE, Geoffrey HA, Timothy JP, Gary CWE. 2001. Arthur's Veterinary Reproduction and Obstetrics, 1 Eighth Editions. Elsevier Health Sciences.

Opsomer G, Grohn YT, Hertl J, Coryn M, Deluyker H, de Kruif A. 2000. Risk factors for post partum ovarian dysfunction in high producing cows in Belgium: A field study. Theriogenology. 53: 841-857.

Pemayun TGO. 2009. Induksi estrus dengan PMSG dan GnRH pada sapi perah anestrus postpartum. Buletin Veteriner Udayana 1(2): 83-87.

Putro P. 2014. Dinamika folikel ovulasi setelah perlakuan sinkronisasi estrus dengan implan progesteron intravagina pada sapi perah. J. Sain Vet. 31(2): 128-137.

Yavas Y, Walton J. 2003. Postpartum acyclicity in suckled beef cows: A review Theriogenology. 54(1): 2555. 